\title{
Magnetic resonance imaging of the infant brain: anatomical characteristics and clinical significance of punctate lesions
}

\author{
L G Cornette, S F Tanner, L A Ramenghi, L S Miall, A M Childs, R J Arthur, D Martinez, \\ M I Levene
}

See end of article for authors' affiliations

.......................

Correspondence to: Dr Cornette, Peter Congdon Neonatal Intensive Care Unit

Clarendon Wing C Floor Leeds General Infirmary, Leeds LS2 9NS, UK;

luc.cornette@leedsth.nhs.uk

Accepted

29 November 2001

\begin{abstract}
Objective: To describe the magnetic resonance imaging (MRI) characteristics of punctate brain lesions in neonates (number, appearance, distribution, and association with other brain abnormalities) and to relate them to neurodevelopmental outcome.

Methods: A retrospective analysis was performed of $110 \mathrm{MRI}$ brain scans from 92 infants admitted in 1998 to the neonatal intensive care unit. Results of routine neurodevelopmental follow up (1998-2001) in those infants with punctate brain lesions were analysed.

Results: Punctate lesions were observed in 15/50 preterm and 2/42 term infants. In the preterm group, the number of lesions was < 3 in $20 \%, 3-10$ in $27 \%$, and $>10$ in $53 \%$. In 14/15 the lesions were linearly organised and located in the centrum semiovale. Other brain abnormalities were absent or minor-that is, "isolated" punctate lesions-in 8/15 and major in 7/15. In the term group, punctate lesions were organised in clusters and no other brain abnormalities were observed. Isolated punctate lesions were observed in 10/17 infants, and a normal neurodevelopmental outcome was seen in 9/10 (mean follow up 29.5 months). One infant showed a slight delay in language development. In the infants with associated brain lesions (7/17, mean follow up 27.5 months), outcome was normal in only two subjects.

Conclusions: Punctate lesions are predominantly seen in preterm infants, are usually linearly organised, and border the lateral ventricles. Isolated punctate lesions may imply a good prognosis, because most of these subjects have a normal neurodevelopmental outcome so far.
\end{abstract}

$\mathrm{T}$ he use of magnetic resonance imaging (MRI) has been successfully extended to the neonatal period over the last decade. At present, MRI data on normal brain development and on a wide range of pathological entities have been collected in both preterm and term infants. ${ }^{1}$ Whereas cranial ultrasound (CUS) has been pivotal in facilitating our understanding of severe white matter injury in the premature infant, such as cystic periventricular leucomalacia (PVL) and intraparenchymal infarctions, optimisation of MRI methods provides us with a finer anatomical resolution, allowing the detection of more discrete abnormalities. ${ }^{2}$ Punctate white matter hyperintensities are a common MRI observation in the elderly, and, according to histopathological correlations, correspond to focal rarefaction of myelin, loss of fibres, or lacunar infarctions. ${ }^{3}$ Only anecdotal reports exist on similar subtle white matter lesions in infants presenting with perinatal asphyxia ${ }^{4-6}$ or seizures. ${ }^{7}$ These lesions vary from hyperintense to hypointense on T2 weighted images and have been interpreted as focal areas of necrosis or haemorrhage. Using MRI, we also recently observed punctate white matter abnormalities in newborns. ${ }^{8}$ These lesions are $<5 \mathrm{~mm}$ in diameter and consist of an increased signal intensity (SI) on $\mathrm{Tl}$ weighted MR images - that is, Tl shortening —and decreased SI on T2 weighted images - that is, T2 shortening. So far, punctate brain lesions in the neonatal age group have not been studied systematically, and their "natural clinical outcome" has remained largely unknown. Hence, the aim of this study was to systematically describe the anatomical characteristics and clinical significance of punctate MRI brain lesions in a large cohort of preterm and term neonates admitted to our neonatal intensive care unit. We analysed all brain MRI scans performed in 1998 to allow at least two years clinical follow up.

\section{METHODS}

\section{Subjects}

In 1998,837 infants were admitted to the neonatal unit of the Leeds General Infirmary (507 infants inborn and 330 infants referred from other hospitals). The unit accepts infants for intensive, medium, and special care (levels of care categories recommended by the British Association of Perinatal Medicine). Of all 1998 admission days, 21\% were categorised as intensive care days. Recruitment for brain MRI was predominantly performed within this group of infants needing intensive care. We obtained consent in 109 infants, the scans of which were analysed retrospectively.

Eighty six of these infants were scanned for clinical indications, such as perinatal asphyxia $(n=24)$, convulsions with causes other than asphyxia (meningitis/encephalitis, MCA infarction, fits of unknown origin, $\mathrm{n}=21$ ), congenital or posthaemorrhagic hydrocephalus (with or without complications such as ventriculitis, $\mathrm{n}=16$ ), dysmorphism with or without brain malformation on CUS and/or chromosomal abnormality $(n=14)$, (severe) PVL $(n=7)$, persistent echodensities on CUS $(n=2)$, congenital infection $(n=1)$, and mitochondrial disorder $(\mathrm{n}=1)$.

The remaining 23 infants all had intravenous access in situ at the time that they were well enough to undergo MRI and were therefore recruited for another continuing MRI research project, measuring brain perfusion. No definite abnormalities were observed on CUS in this group. Although there was no

Abbreviations: $M R I$, magnetic resonance imaging; CUS, cranial ultrasound; PVL, periventricular leucomalacia; SI, signal intensity; GA, gestational age 
specific clinical indication in these infants for brain MRI, 15 of these 23 babies were given intensive care in the neonatal period.

Anatomical MRI details were obscured by movement artefact in 17 subjects. Therefore 92 of the subjects were included for full MRI analysis ( 48 boys, 44 girls; 54 inborn, 38 referred; 71 scanned for clinical reasons, 21 for research purposes). Informed consent for the scan was obtained on all occasions and the MRI procedure was approved by the research ethics committee of the Leeds General Infirmary.

We classified the 92 subjects into two different groups: (1) preterm infants (gestational age $(\mathrm{GA})<37$ weeks, $\mathrm{n}=50$ ); (2) term infants ( $G A \geqslant 37$ weeks, $n=42$ ). The median birth weight of the preterm infants was $1280 \mathrm{~g}$ (SD 739, range 5803675) for a median GA of 30 weeks (SD 3.5, range 25-36). The median birth weight of the term infants was $3160 \mathrm{~g}$ (SD 715, range 2035-4430) for a median GA of 40 weeks (SD 1.4, range 37-41). Median age at MRI in the preterm group was 13 days (SD 24, range 2-106). Median age at MRI in the term group was 14 days (SD 64, range 2-273).

A repeat scan was performed only when further characterisation of an observed MRI abnormality was essential as part of clinical management, and was obtained in 18 of the subjects (12 preterm and six term infants).

\section{MRI acquisition}

All infants underwent the same imaging protocol on a $1.5 \mathrm{~T}$ Gyroscan ACS-NT (Philips Medical Systems, Eindhoven, The Netherlands), with a receive only quadrature head coil. Firstly, Tl weighted spin echo images were acquired in the sagittal and axial planes. The acquisition parameters used to acquire the Tl weighted images were: repetition time 800 milliseconds; echo time 13 milliseconds; field of view $180 \mathrm{~mm}$; slice thickness $4 \mathrm{~mm}$ with a $0.4 \mathrm{~mm}$ gap; acquisition matrix $256 \times$ 256; scan time 3 min 52 seconds. Secondly, T2 weighted fast spin echo images were acquired in the axial plane. The parameters used were: repetition time 6000 milliseconds; echo time 200 milliseconds; echo train length 13; field of view $180 \mathrm{~mm}$; slice thickness $3 \mathrm{~mm}$ with a $0.3 \mathrm{~mm}$ gap; acquisition matrix $256 \times 256$; scan time 5 min 12 seconds. Thirdly, because of its superior sensitivity to acute injury, MRI diffusion measurements were attempted when evidence obtained from the Tl and $\mathrm{T} 2$ weighted images indicated that the infants were not moving. An orientation independent measure of the apparent diffusion coefficient was obtained by calculating the average of three orthogonal diffusion measurements. ${ }^{9}$ The protocol consisted of a multishot spin echo echoplanar imaging sequence that was electrocardiographically triggered. A navigator echo was used to reduce motion artefacts. The parameters used were echo time 105 milliseconds, slice thickness $6 \mathrm{~mm}$ with a $1 \mathrm{~mm}$ gap, field of view $180 \mathrm{~mm}$, and acquisition matrix $256 \times 256$.

All scans were performed after a feed, and most infants were imaged without the use of sedation. If necessary, subjects were sedated with $30-50 \mathrm{mg} / \mathrm{kg}$ chloral hydrate administered orally. They were continuously monitored by pulse oximetry and electrocardiographic recording. Mechanical ventilation, continuous positive airway pressure, and administration of intravenous fluids and inotropic drugs were continued if necessary. Blankets wrapped around the babies kept them warm during scanning, and cotton wool placed in their ears diminished the effects of gradient generated noise. The head was immobilised by a pillow filled with polystyrene balls and moulded into shape by vacuum extraction. This reduced image artefacts arising from head movement. A paediatrician was present during the transfer of babies between the neonatal unit and the scanner, and throughout the MRI study.

\section{MRI analysis}

The MRI scans were viewed on a Philips Easyvision stand alone workstation, using proprietary software, by four trained investigators (LGC, LSM, RJA, DM) blinded to the clinical data of study participants. A standardised system of visual assessment was used to describe each scan, and consensus was reached for each infant. Punctate lesions were defined as spots $(<5 \mathrm{~mm})$ of increased SI on $\mathrm{Tl}$ weighted images and decreased SI on T2 weighted images. Features recorded included (a) number of punctate lesions (categorised into $<3$, $3-10,>10),(b)$ appearance of the lesions (organised in clusters-that is, a confluent pattern-, linearly or mixed-type pattern), and (c) location (anterior to the frontal horn of the lateral ventricles (anterior region), posterior to the occipital horn of the lateral ventricles (posterior region), or in between (mid-region or centrum semiovale); and observed unilaterally or bilaterally). This location strategy was based on our expectation that anterior located lesions would remain asymptomatic in a neonate, because the anterior frontal cortex shows little metabolic activity at this stage of development. ${ }^{10}$ In contrast, a lesion located in the centrum semiovale may cause motor dysfunction during follow up. In addition, possible association with other brain abnormalities defined as minor (cortical highlighting, intraventricular haemorrhage grade I or IIa, ${ }^{11}$ discrete oedema) or major (intraventricular haemorrhage grade IIb or III," venous infarction zones, cystic PVL, extensive cortical atrophy, and ventricular dilatation) was investigated.

\section{Follow up strategy}

All infants admitted to our neonatal unit are subjected to regular clinical follow up, at either Leeds General Infirmary or the referring hospital. Our policy is to follow up all inborn infants who received intensive care, until they reach the age of two years. Infants referred from other centres are normally followed up at the referring hospital, unless under the care of a tertiary specialist. The infants are seen at regular intervals (three to six months). Neurodevelopmental assessment focuses on the achievement of developmental milestones, using standard questions in the gross motor, person-social, language, and fine motor-adaptive realms. Apart from a general physical examination, the neurological examination involves careful examination of the skull, cranial nerves, posture, muscle tone, reflexes, power, coordination, and sensory system. All neonatologists involved are experienced in standard clinical neurological examination and forward their observations on a regular basis to the consultants at Leeds General Infirmary.

\section{RESULTS}

\section{MRI analysis in preterm infants $(n=50)$}

Punctate abnormalities were observed in 15/50 ( 10 boys, five girls) preterm infants (table $1 \mathrm{~A}, \mathrm{~B}$ ). The median birth weight was $1320 \mathrm{~g}$ (SD 929, range 580-3960), and the median GA 31 weeks (SD 2.9, range 27-36). Median age at MRI was 16 days (SD 20.4, range 2-82). The median postconceptional age at MRI was 35 weeks (SD 3.1, range 29-39.7). Individual details of antenatal (maternal systemic diseases, obstetric risk factors, intrauterine growth retardation) and perinatal (type of delivery, Apgar scores) events are summarised (table 1). Except for premature delivery, pregnancy was uneventful in six. Six subjects were delivered by emergency caesarean section for fetal distress, and all 15 subjects needed intensive care during the first week(s) of life.

All punctate lesions were located in the white matter. The number of lesions was $<3$ in three (all clusters), 3-10 in four (two linearly organised, two mixed-type pattern), and $>10$ in eight ( six linearly organised). The lesions were seen in the mid $(n=14)$, posterior $(n=8)$, and anterior $(n=3)$ regions of the brain. All clusters were localised in one hemisphere, whereas all linear or mixed-type lesions were observed bilaterally. In four babies, no other brain abnormality was seen (fig lA), in four babies punctate lesions were associated with 


\begin{tabular}{|c|c|c|c|c|c|c|c|c|c|c|c|c|c|c|c|c|c|c|}
\hline \multirow[b]{4}{*}{ Patients } & \multirow[b]{4}{*}{ Sex } & \multirow[b]{4}{*}{ Antenatal } & & & & & \multicolumn{10}{|c|}{ MRI and characterisation of punctate lesions } & & \\
\hline & & & & & & & \multirow[b]{3}{*}{ Age (days) } & \multirow[b]{3}{*}{ Number } & \multirow[b]{3}{*}{ Appearance } & \multicolumn{6}{|c|}{ Distribution } & \multirow[b]{3}{*}{ Associated lesions } & \multirow{2}{*}{\multicolumn{2}{|c|}{ Follow up }} \\
\hline & & & \multicolumn{4}{|l|}{ Perinatal } & & & & \multicolumn{2}{|c|}{ Ant region } & \multicolumn{2}{|c|}{ Mid region } & \multicolumn{2}{|c|}{ Post region } & & & \\
\hline & & & GA (weeks) & Weight (g) & Delivery & Neonatal events & & & & u & B & $u$ & B & u & B & & $\begin{array}{l}\text { Age at last } \\
\text { exam } \\
\text { (months) }\end{array}$ & $\begin{array}{l}\text { Neurological } \\
\text { outcome }\end{array}$ \\
\hline${ }^{A}{ }_{1}$ & M & Hypothyroidium & 28 & 1220 & SVD & Ventilated 3 days & 7 & $>10$ & Mixed & & & & + & & + & - & 14 & $\mathrm{~N}$ \\
\hline \multirow{2}{*}{$\begin{array}{l}3 \\
2\end{array}$} & & & & & & & & & & & & & & & & & & \\
\hline & M & $\begin{array}{l}\text { Premature rupture of } \\
\text { membranes }\end{array}$ & 32 & 2130 & SVD & Ventilated 2 days & 3 & $>10$ & Linear & & & & + & & + & Oedema & 23 & $\mathrm{~N}$ \\
\hline 3 & $\mathrm{~F}$ & $\mathrm{~N}$ & 28 & 1110 & EICS & $\begin{array}{l}\text { Ventilated } 2 \text { days } \\
\text { Colonic perforation }\end{array}$ & 82 & $>10$ & Linear & & & & + & & & Oedema & 18 & $\mathrm{~N}$ \\
\hline 4 & $\mathrm{~F}$ & $\mathrm{~N}$ & 30 & 1700 & SVD & $\begin{array}{l}\text { Ventilated } 3 \text { hours } \\
\text { CUS day 2: IVH grade IIIb }\end{array}$ & 9 & $3-10$ & Linear & & & & + & & & Oedema & 25 & $\begin{array}{l}\text { Discrete delay } \\
\text { in language }\end{array}$ \\
\hline 5 & M & Polyhydramnion & 36 & 2540 & SVD & $\begin{array}{l}\text { Collapse due to atrial tachycardia } \\
\text { Hypothyroidism }\end{array}$ & 13 & $3-10$ & Cluster & & & + & & & & - & 20 & $\mathrm{~N}$ \\
\hline 6 & M & $\begin{array}{l}\text { Pre-eclampsia } \\
\text { IUGR }\end{array}$ & 27 & 580 & $\mathrm{EmCS}$ & $\begin{array}{l}\text { CUS day 2: IVH grade lllb } \\
\text { Hypotension }\end{array}$ & 44 & $<3$ & Cluster & & & & & + & & Oedema & 23 & $\mathrm{~N}$ \\
\hline 7 & $\mathrm{~F}$ & Hypertension & 31 & 1360 & $\mathrm{EmCS}$ & Ventilated 2 days & 7 & $<3$ & Cluster & & & + & & & & - & 22 & N \\
\hline 8 & $\mathrm{~F}$ & $\begin{array}{l}\text { Hypertension } \\
\text { IUGR }\end{array}$ & 34 & 1260 & EICS & Resuscitation at birth & 2 & $<3$ & Cluster & & & + & & & & - & 18 & $\mathrm{~N}$ \\
\hline \multirow{2}{*}{${ }^{B} 9$} & & & & & & & & & & & & & & & & & & \\
\hline & M & $\mathrm{N}$ & 35 & 1875 & SVD & $\begin{array}{l}\text { Perforated necrotising } \\
\text { enterocolitis }\end{array}$ & 27 & $>10$ & Cluster & & & + & & + & & $\begin{array}{l}\text { Cerebellar } \\
\text { hemorrhage }\end{array}$ & 16 & $\mathrm{~N}$ \\
\hline 10 & M & $\mathrm{N}$ & 30 & 1320 & SVD & $\begin{array}{l}\text { Ventilated 1 day } \\
\text { CUS day 7: bilateral PVL }\end{array}$ & 13 & $>10$ & Linear & & + & & + & & + & Cystic PVL & - & Died \\
\hline 11 & $\mathrm{~F}$ & N & 29 & 1150 & $\mathrm{EmCS}$ & CUS day 2: IVH grade lllb & 26 & $>10$ & Linear & & & & + & & + & Cystic PVL & 15 & Cerebral palsy \\
\hline 12 & M & Gestational diabetes & 36 & 3960 & $\mathrm{EmCS}$ & Resuscitation at birth & 12 & $>10$ & Mixed & & + & & + & & + & $\begin{array}{l}\text { Basal ganglia } \\
\text { hemorrhage }\end{array}$ & 19 & $\mathrm{~N}$ \\
\hline 13 & M & Discordant twins & 30 & 1200 & $\mathrm{EmCS}$ & CUS week 2: bilateral PVL & 29 & $>10$ & Linear & & & & + & & + & Cystic PVL & 20 & Cerebral palsy \\
\hline 14 & M & IUGR & 33 & 1200 & EmCS & $\begin{array}{l}\text { CUS day 1: IVH grade lllb } \\
\text { Leff renal vein thrombosis }\end{array}$ & $\begin{array}{l}18 \\
25\end{array}$ & $\begin{array}{l}3-10 \\
-\end{array}$ & $\begin{array}{l}\text { Mixed } \\
-\end{array}$ & & + & & + & & & Cystic PVL & 16 & Cerebral palsy \\
\hline 15 & M & $\mathrm{N}$ & 33 & 3430 & SVD & $\begin{array}{l}\text { Fits day } 13 \text { due to } \\
\text { herpefic encephal itis }\end{array}$ & 19 & $3-10$ & Cluster & & & + & & & & $\begin{array}{l}\text { Herpetic } \\
\text { encephalitis }\end{array}$ & 26 & $\begin{array}{l}\text { Cerebral palsy } \\
\text { Epilepsy }\end{array}$ \\
\hline c & & & & & & & & & & & & & & & & & & \\
\hline 16 & $\mathrm{~F}$ & $\mathrm{~N}$ & 40 & 3025 & SVD & $\begin{array}{l}\text { Incontinentia pigmenti } \\
\text { Fits day } 5 \text {, EEG normal }\end{array}$ & 51 & $>10$ & Cluster & & + & & & & & - & 24 & N \\
\hline 17 & $\mathrm{~F}$ & $\mathrm{~N}$ & 40 & 3055 & SVD & $\begin{array}{l}\text { CUS day 1: subarachnoid } \\
\text { haemorrhage }\end{array}$ & $\begin{array}{l}6 \\
34\end{array}$ & $\begin{array}{l}<3 \\
-\end{array}$ & Cluster & & & & & + & & $\begin{array}{l}\text { Subarachnoid } \\
\text { haemorrhage }\end{array}$ & 15 & $\mathrm{~N}$ \\
\hline
\end{tabular}



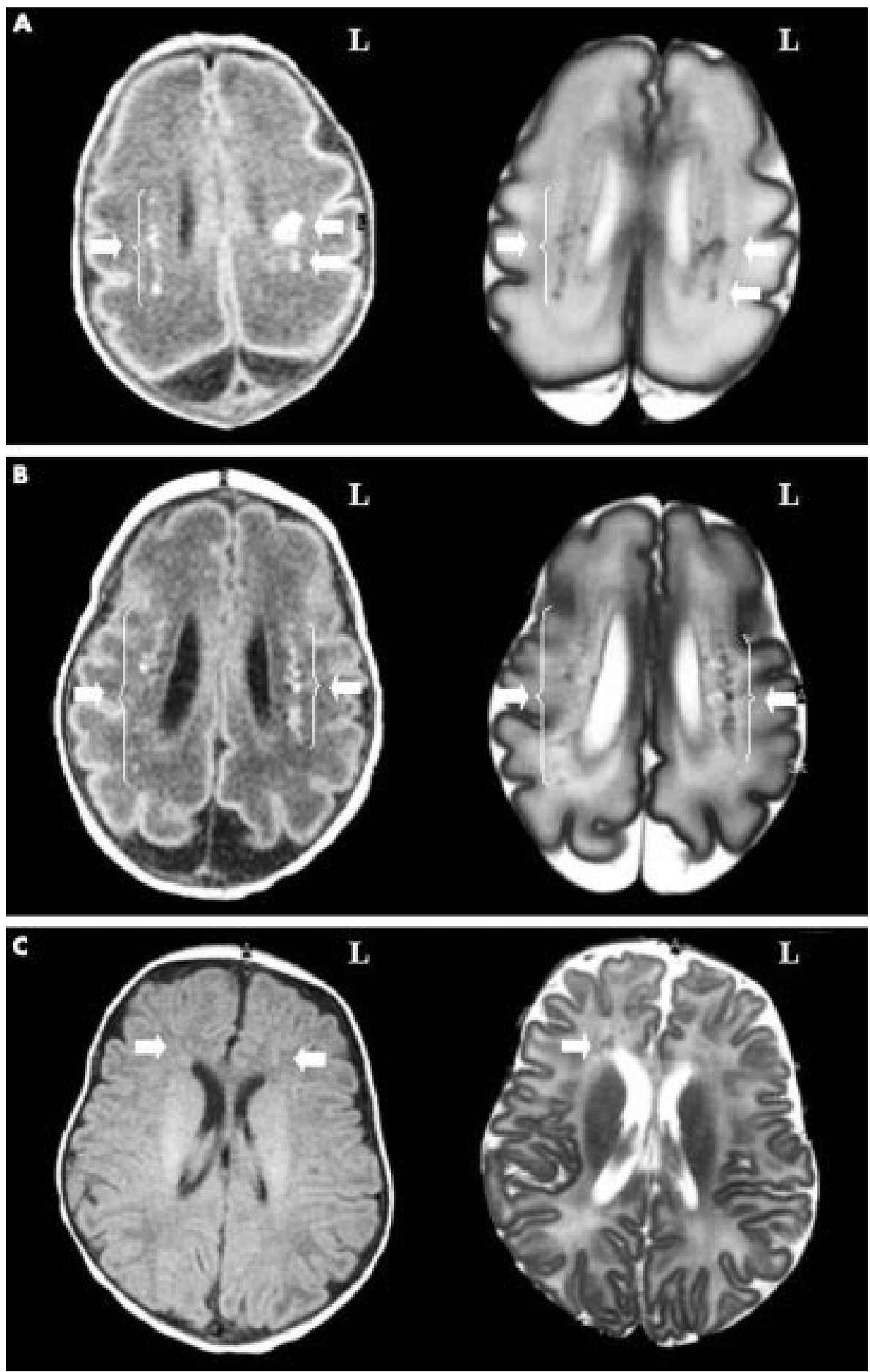

Figure 1 Magnetic resonance characterisation of punctate lesions. (A) Isolated punctate lesions in an infant of 28 weeks gestation, scanned at 7 days of age (corresponding to case 1 in table 1). Left panel: T1 weighted axial image through the body of the lateral ventricles. Bilateral high intensity spots (arrows) correspond to punctate lesions, predominantly seen in the mid and posterior regions of the brain. In the right hemisphere, lesions (about 10) are linearly organised in the periventricular white matter. In the left hemisphere, lesions are organised in a mixed-type pattern (clustered and linear). No other brain abnormalities are observed. L, Left. Right panel: corresponding T2 weighted axial image of same infant. Bilateral low intensity spots (arrows) correspond to punctate lesions. (B) Punctate lesions in an infant of 29 weeks gestation with cystic periventricular leucomalacia (PVL), scanned at 26 days of age (corresponding to case 11 in table 1). Left panel: T1 weighted axial image through the body of the lateral ventricles. Bilateral high intensity spots (arrows) correspond to punctate lesions, predominantly seen in the mid and posterior regions of the brain. In the two hemispheres, the lesions are linearly organised and border a medially located discrete band of low signal intensity lesions in the periventricular white matter. Right panel: corresponding T2 weighted axial image of same infant. Bilateral low intensity spots (arrows) correspond to punctate lesions. The punctate lesions are clearly neighbouring a medial region of cystic PVL (high intensity lesions, corresponding to cystic degeneration). (C) Isolated punctate lesions in an infant of 40 weeks gestation, scanned at 51 days of age (corresponding to case 16 in table 1). Left panel: T1 weighted axial image through the body of the lateral ventricles. Bilateral high intensity spots (arrows) correspond to punctate lesions, exclusively seen in the anterior region of the brain. No anatomical or myelination abnormalities are observed. Right panel: corresponding T2 weighted axial image of same infant. Low intensity spots (arrow) correspond to punctate lesions. In the right hemisphere, a cluster of six lesions is observed, whereas only one spot is clearly distinguished on the T1 weighted image. 

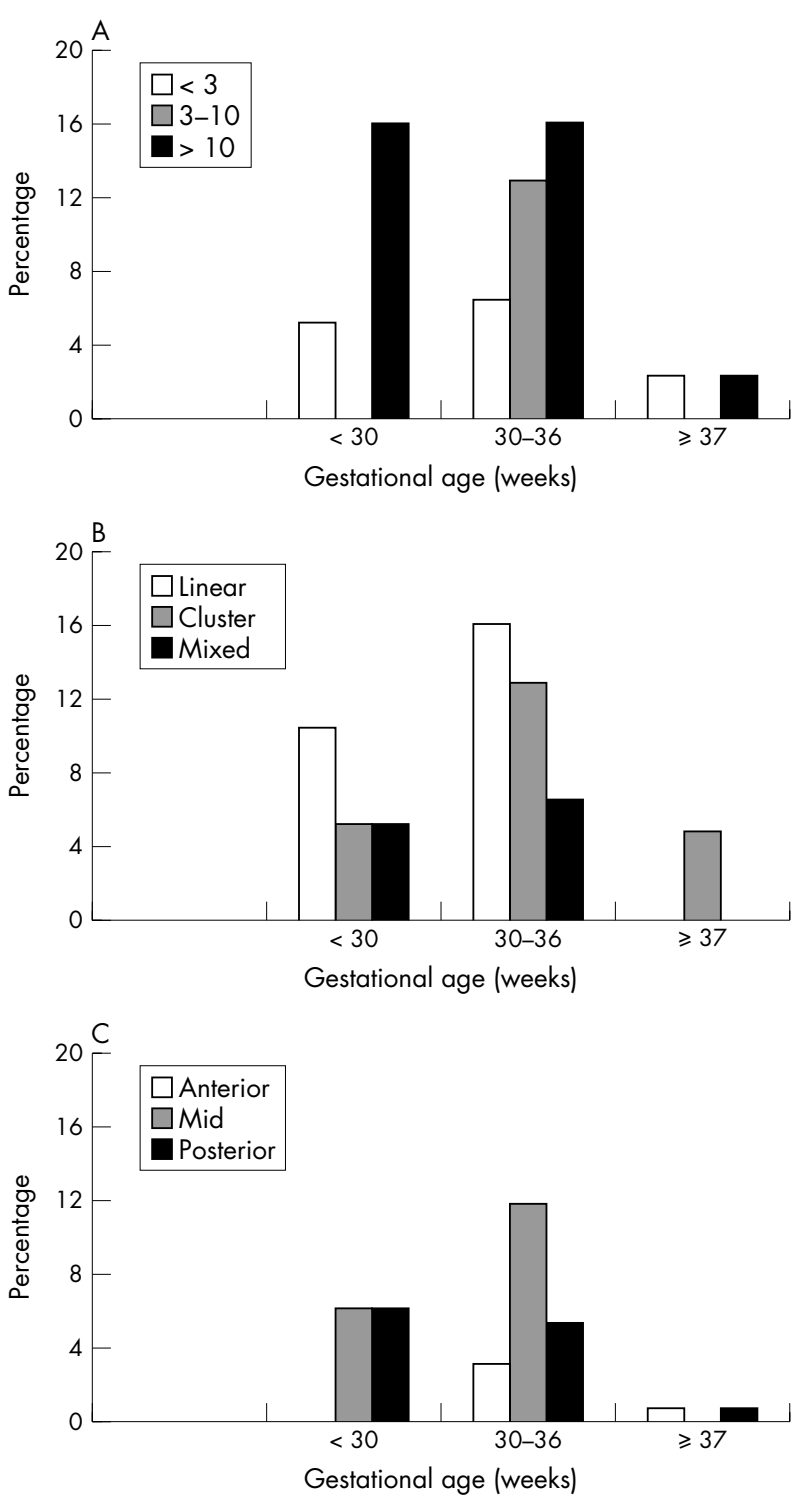

Figure 2 Overview of punctate lesions. Results are grouped according to the gestational age of all subjects analysed $(n=92)$ : $<30$ weeks $(n=19)$, between 30 and 36 weeks $(n=31)$, and $\geqslant 37$ weeks $(n=42)$. (A) Number of punctate lesions. The percentage of cases with $<3,3-10$, or $>10$ lesions is plotted for the different groups. (B) Appearance of punctate lesions. The percentage of cases with linear, clustered, or mixed appearance is plotted for the different groups. (C) Topography of punctate lesions. The percentage of cases in the anterior, mid, or posterior region of the brain is plotted for the different groups. As lesions were observed in the anterior, mid, and posterior region of the brain, we multiplied the total number of cases by three to calculate the percentage.

minor abnormalities (discrete oedema), and in seven babies there were other major lesions (cystic PVL, left cerebellar haemorrhage, infarction in the basal ganglia, and herpetic encephalitis; fig 1B). In one subject with cystic PVL, a repeat scan performed seven days after the first one showed that the punctate lesions had disappeared. No punctate lesions were identified in 35/50 (22 girls, 13 boys) preterm infants. Within this group, no brain abnormalities were observed in 18, minor abnormalities were seen in four, and major abnormalities in 13. The other abnormalities in the 13 subjects included loss of parenchymal detail because of extensive cyst formation or gross posthaemorrhagic hydrocephalus. No congenital brain malformations were seen.
MRI analysis in term infants $(n=42)$

Punctate abnormalities were seen in only two of the term infants (both girls, GA $=40$ weeks, birth weights 3025 and $3055 \mathrm{~g}$; table 1C). In both subjects, the lesions were organised in clusters. In one subject, we observed $>10$ punctate lesions, present in both hemispheres (fig lC), while in the other $<3$ lesions were observed, confined to the left hemisphere. The latter subject had also suffered a subarachnoid haemorrhage. Interestingly, a further scan four weeks later indicated that both the haemorrhage and punctate lesions had completely disappeared. No congenital brain malformations were seen in any of the term subjects.

\section{MRI diffusion measurements}

We acquired average diffusion weighted images in five of the ten babies (eight preterm and two term) with isolated punctate lesions (no or only minor other brain lesions). The diffusion weighted images did not show any corresponding abnormalities.

\section{Overview}

Figure 2 summarises all characteristics of the lesions. We divided the cohort $(n=92)$ into three subgroups: (a) GA $<30$ weeks $(n=19)$, (b) GA between 30 and 36 weeks $(n=31)$, and (c) $G A \geqslant 37$ weeks $(n=42)$. Babies with more than 10 lesions were predominantly observed in groups a and $\mathrm{b} ; 3-10$ lesions were observed only in group $\mathrm{b} ;<3$ lesions were observed across all three groups ( fig 2A). Predominantly linear lesions were observed in preterm infants with punctate lesions (groups a and b), followed by a cluster-type pattern; $\mathrm{a}$ mixed-type pattern was seen in only three subjects (fig $2 \mathrm{~B}$ ). Most of the cases were observed in the mid region of the brain, present across all preterm ages; fewest lesions appeared in the anterior region (fig 2C).

\section{Neurodevelopmental outcome}

No subjects were lost to follow up during the study. The mean follow up time of all preterm and term infants with isolated punctate lesions $(\mathrm{n}=10)$ is currently 29.5 months (SD 3.5, range 23.2-34.1). So far, their neurodevelopmental outcome is favourable (table $\mathrm{IA}, \mathrm{C}$ ): no subject died, no motor impairments have been noted, and only a slight delay in language development was seen in one girl at the age of 34.1 months. The clinical outcome of subjects with punctate lesions and other major lesions-that is, all preterm born infants $(\mathrm{n}=7)$-is less favourable (table $1 \mathrm{~B})$. The mean follow up time in this group is currently 27.5 months (SD 3.9, range 24.4-34.8). So far, clinical evaluation is normal in the two subjects with a haemorrhage, while cerebral palsy (spastic diplegia or quadriplegia) developed in three subjects with cystic PVL and in the subject with herpetic encephalitis. One subject with severe cystic PVL died at the age of 3.5 weeks. Hence, outcome in the latter group seems to be largely dependent on the severity and extent of the associated non-punctate lesions.

\section{DISCUSSION}

In this study, we identified the MRI characteristics of punctate brain lesions in a large cohort of neonates and infants $(\mathrm{n}=92)$. The lesions were identified on the basis of focal increases (T1 weighted) and decreases (T2 weighted) in SI. In addition, we related the lesions to neurodevelopmental outcome.

\section{MRI characteristics of punctate brain lesions}

This study was not designed as an epidemiological survey of the prevalence of white matter abnormalities, as we studied a cohort of preterm and term babies, with and without clinical problems. Although we do not imply that punctate lesions are a common condition across all infants, our study indicates 
that they are not uncommonly observed in infants requiring neonatal intensive care. In the subjects analysed, they predominantly occurred in preterm infants $(88 \%)$, the youngest infant having a postconceptional age of 29 weeks at the time of the scan. In most subjects, we observed $>10$ discrete punctate lesions, although in subjects with associated brain damage the number of punctate lesions may have been underestimated because of extensive colateral tissue damage. In the most preterm group (postconceptional age $<33$ weeks), the lesions were most commonly linearly organised, whereas in older infants (postconceptional age $>33$ weeks), lesions were organised more in clusters. Most lesions were observed in the mid region of the brain - that is, bordering the lateral ventricles in the centrum semiovale.

The punctate lesions described in this study clearly differ from at least three other subtle changes in SI observed in the frontal white matter of infants. Firstly, they differ from the subtle structures of reduced SI observed bilaterally in the frontal periventricular white matter of the premature brain (T2 weighted images). These more band-like structures reflect the normal brain maturation phenomenon of groups of glial cells migrating to the cortex. ${ }^{6}{ }^{12}$ Secondly, the currently described punctate lesions are different from the symmetrical focal areas of high $\mathrm{T} 1$ weighted and low T2 weighted SI that are restricted to the frontal horns of both hemispheres and which are believed to correspond to remnants of the germinal matrix. ${ }^{13}$ Thirdly, their SI is clearly different from frontal white matter punctate pseudolesions. ${ }^{14}$ These lesions have a high SI on $\mathrm{T} 2$ weighted images and are thought to occur because of a locally decreased myelin content, increased periependymal water collection, and ependymitis granularis.

\section{Are punctate brain lesions petechial haemorrhages?}

One should be cautious in inferring the exact nature of punctate lesions in infants. Indeed, no histological specimen was available in our cohort of infants, because parents of the infant with cystic PVL who died did not give consent for a postmortem examination. However, there are a number of reasons that make us believe punctate lesions correspond to petechial or focal areas of haemorrhage. Firstly, a repeat MRI scan, although obtained in only two subjects with established lesions, indicates that punctate lesions probably do not reflect local areas of permanent tissue destruction because they disappeared in both cases. Secondly, the fact that the lesions were seen slightly more clearly on $\mathrm{T} 2$ weighted images than on $\mathrm{Tl}$ weighted images corresponds to the observation that haemoglobin degradation products cause T2 shortening before they cause T1 shortening. ${ }^{15}$ Other causes of $\mathrm{T} 1$ and $\mathrm{T} 2$ shortening have been suggested, including haemosiderin deposition, ${ }^{4}$ dystrophic calcification, and presence of lipids from myelin breakdown. ${ }^{16}$ These are less likely because of the seemingly short lived and benign nature of the punctate lesions in the current study group. Interestingly, the predominantly linear organisation of isolated punctate lesions in preterm infants, bordering the lateral ventricles and involving particularly the centrum semiovale, corresponds to the distribution of PVL injury seen in preterm infants. ${ }^{17}$ Cystic PVL was the most commonly observed associated lesion. It is uncertain whether the punctate lesions are part of the pathophysiology of PVL, as they were also observed in two term infants, although in the anterior part of the brain. However, discrete haemorrhage into PVL lesions has been described in autopsy specimens and is, most commonly, petechial and circumscribed in nature. ${ }^{18}$ As lesions smaller than $5 \mathrm{~mm}$ are largely missed by CUS, ${ }^{4}$ one could argue that, at least in the premature infants, the punctate lesions may correspond to PVL grade I-that is, a transient hyperechogenicity of white matter that resolves without cyst formation. ${ }^{19}$ As most of the current MR images were acquired later than the CUS images, we did not compare the two imaging modalities in detail. At least in the isolated cases of punctate lesions, no obvious changes in echodensity were observed in the available CUS images. However, it is possible that, for each abnormal finding, there is a different optimal time for identification. ${ }^{16}$ In addition, the diffusion weighted images did not show any evidence of corresponding petechial abnormalities. Although MRI diffusion measurements in neonates are known to be sensitive to hypoxic ischaemic encephalopathy, the appearance of abnormalities depends on the relative timing of the MRI examination and the ischaemic insult. ${ }^{20}$ The failure to detect punctate abnormalities in diffusion data may therefore relate to the timing of the MRI examination, the large voxel sizes $(1.4 \mathrm{~mm} \times 1.4 \mathrm{~mm}$ $\times 6 \mathrm{~mm}$ ) used, and/or the relatively low levels of signal intensity obtained.

\section{Clinical significance of punctate brain lesions}

In elderly normal subjects, a recent three year follow up study of these punctate lesions did not indicate an association between punctate lesions and cognitive functioning. ${ }^{3}$ In infants with large lesions such as cerebral infarctions, it has been shown that the detection of an abnormal sign during early neonatal neurological examination is a poor prognostic indicator. ${ }^{7}$ So far, punctate brain lesions in the neonatal age group have not been studied systematically. Early and follow up MRI studies in either premature or term infants with perinatal brain damage are, however, useful tools in predicting early and late clinical outcome..$^{21-25}$ In our study, we carefully monitored neurodevelopment of all infants with isolated punctate brain lesions, which was normal in most (9/10, mean follow up 29.2 months). This favourable outcome was not introduced by subject selection bias, as intensive care treatment-for example, mechanical ventilation, resuscitation, or gastro-intestinal surgery-was needed in all infants. Hence, one can be optimistic when counselling parents about the risk of their babies having an abnormal neurological outcome. This is in agreement with the observation that minor CUS abnormalities identified within the first 96 hours of life, such as a mild ventricular enlargement, choroid plexus cyst, or subependymal cyst, mostly have no clinical significance in the immediate neonatal period, although they may cause several subtle abnormalities in behaviour beyond the neonatal period. ${ }^{26}$ On the other hand, subtle neurological disturbances such as asymmetry in tone or reflexes can be difficult to demonstrate in neonates and infants. ${ }^{27}$

Although we are currently expanding the cohort of infants studied by investigating all MRI brain scans performed after 1998, this report discusses only those performed in 1998, because it provided us with at least two years of clinical follow up. We accept that two years of follow up is still too short to determine whether or not punctate lesions can predict a more subtle clinical deficit. In time, it may be that the largely "asymptomatic" punctate brain abnormalities, already detectable on MRI scans during neonatal life, will be associated with mild cognitive deficits at school age. Therefore, we plan a thorough neuropsychological evaluation in all 10 children at the age of 5 (Wechsler preschool and primary scale of intelligence to assess cognitive functioning; revised and movement $\mathrm{ABC}$ to assess motor functioning). Because of the rapid advances currently obtained in MR image resolution through the use of head coils specifically adapted for infants or children and the improving resolution of diffusion weighted imaging, ${ }^{28} 29$ this neuropsychological evaluation will be combined with a repeat MRI investigation. The true significance of punctate brain lesions will only become apparent once there has been a sufficiently long period of follow up.

\section{ACKNOWLEDGEMENTS}

We are much indebted to all staff of the neonatal unit and the MRI department for their assistance. This work was supported by a grant from the special Trustees of the Leeds General Infirmary and from the Rotary Foundation. LC is a Consultant Neonatologist. 


\section{Authors' affiliations}

L G Cornette, L A Ramenghi, L S Miall, A M Childs, M I Levene, Department of Paediatrics and Child Health, Leeds General Infirmary, Leeds, UK

S F Tanner, Department of Medical Physics and Centre of Medical Imaging Research, University of Leeds and Leeds General Infirmary R J Arthur, D Martinez, Department of Paediatric Radiology, Leeds General Infirmary

\section{REFERENCES}

1 Barkovich AJ. Normal development of the neonatal and infant brain, skull and spine. In: Barkovich AJ, ed. Pediatric neuroimaging. Philadelphia: Lippincott Williams \& Wilkins, 2000:13-69.

2 Huppi PS, Inder TE. Magnetic resonance techniques in the evaluation of the perinatal brain: recent advances and future directions. Semin Neonatol 2001;6:195-210

3 Schmidt R, Fazekas F, Kapeller $P$, et al. MRI white matter hyperintensities: three-year follow-up of the Austrian Stroke Prevention Study. Neurology 1999;53:132-9

4 Keeney SE, Adcock EW, McArdle CB. Prospective observations of 100 high-risk neonates by high-field (1.5 Tesla) magnetic resonance imaging of the central nervous system. II. Lesions associated with hypoxic-ischemic encephalopathy. Pediatrics 1991;87:431-8.

5 Baenziger O, Martin E, Steinlin M, et al. Early pattern recognition in severe perinatal asphyxia: a prospective MRI study. Neuroradiology 1993;35:437-42.

6 Battin MR, Maalouf EF, Counsell SJ, et al. Magnetic resonance imaging of the brain in very preterm infants: visualization of the germinal matrix, early myelination, and cortical folding. Pediatrics 1998;101:957-62.

7 Mercuri E, Rutherford M, Cowan F, et al. Early prognostic factors of outcome in infants with neonatal cerebral infarction: a clinical, electroencephalogram, and magnetic resonance imaging study. Pediatrics 1999; 103:39-46.

8 Childs AM, Cornette LG, Ramenghi LA, et al. Magnetic resonance and cranial ultrasound characteristics of periventricular white matter abnormalities in newborn infants. Clin Radiol 2001;56:647-55.

9 Tanner SF, Ramenghi LA, Ridgway JP, et al. Quantitative comparison of intrabrain diffusion in adults and preterm and term neonates and infants. AJR Am J Roentgenol 2000; 174: 1643-9.

10 Chugani HT, Phelps ME, Mazziotta JC. Positron emission tomography study of human brain functional development. Ann Neurol 1987:22:487-97.

11 De Vries LS, Rademaker KJ, Groenendaal F, et al. Correlation between neonatal cranial ultrasound, MRI in infancy and neurodevelopmental outcome in infants with a large intraventricular haemorrhage with or without unilateral parenchymal involvement. Neuropediatrics 1998;29:180-8.

12 Childs AM, Ramenghi LA, Evans DJ, et al. MR features of developing periventricular white matter in preterm infants: evidence of glial cell migration. Am J Neuroradiol 1998;19:971-6.
13 van Wezel-Meijler G, van der Knaap MS, Sie LTL, et al. Magnetic resonance imaging of the brain in premature infants during the neonatal period. Normal phenomena and reflection of mild ultrasound abnormalities. Neuropediatrics 1998;29:89-96.

14 Sze G, De Armond SJ, Brant-Zawadzki M, et al. Foci of MRI signal (pseudo lesions) anterior to the frontal horns: histologic correlations of a normal finding. ANNR Am J Neuroradiol 1986;147:331-7.

15 Gomori JM, Grossman Rl, Goldberg HI, et al. Intracranial hematomas: imaging by high-field MR. Radiology 1985;157:87-93.

16 Ernst M, Barkovich AJ. Magnetic resonance imaging in perinatal asphyxia. Arch Dis Child Fetal Neonatal Ed 1995;72:F62-70.

17 De Vries LS, Connell JA, Dubowitz LMS. Neurological, electrophysiological and MRI abnormalities in infants with extensive cystic leukomalacia. Neuropediatrics 1987;18:61-6.

18 Armstrong D, Norman MG. Periventricular leukomalacia in neonates: complications and sequelae. Arch Dis Child 1974;49:367-75.

19 De Vries LS, Eken P, Dubowitz LMS. The spectrum of leukomalacia using cranial ultrasound. Behav Brain Res 1992;49:1-6.

20 Robertson RL, Ben-Sira L, Barnes PD, et al. MR line-scan diffusion-weighted imaging of term neonates with perinatal brain ischemia. ANNR Am J Neuroradiol 1999;20: 1658-70.

21 Aida N, Nishimura G, Hachiya $Y$, et al. MR imaging of perinatal brain damage: comparison of clinical outcome with initial and follow-up MR findings. ANRR Am J Neuroradiol 1998;19:1909-21.

22 Byrne $\mathbf{P}$, Welch R, Johnson MA, et al. Serial magnetic resonance imaging in neonatal hypoxic-ischemic encephalopathy. J Pediatr 1990; 117:694-700

23 Millet V, Bartoli JM, Lacroze V, et al. Predictive significance of magnetic resonance imaging at 4 months of adjusted age in infants after a perinatal neurologic insult. Biol Neonate 1998;73:207-19.

24 Rutherford MA, Pennock JM, Schwieso J, et al. Hypoxic-ischaemic encephalopathy: early and late magnetic resonance imaging findings in relation to outcome. Arch Dis Child Fetal Neonatal Ed 1996;75:F145-51

25 Rutherford MA, Pennock JM, Counsell SJ, et al. Abnormal magnetic resonance signal in the internal capsule predicts poor neurodevelopmental outcome in infants with hypoxic-ischemic encephalopathy. Pediatrics 1998;102:323-8.

26 Behnke M, Eyler FD, Garvan CW, et al. Cranial ultrasound abnormalities identified at birth: their relationship to perinatal risk and neurobehavioral outcome. Pediatrics 1999;103:e41

27 Aicardi J. Fetal and neonatal neurology. In: Bax MCO, Sr ed. Diseases of the nervous system in childhood. London: Mac Keith Press, 1998:32-66.

28 Cowan FM, Pennock JM, Hanrahan JD, et al. Early detection of cerebral infarction and hypoxic ischemic encephalopathy in neonates using diffusion-weighted magnetic resonance imaging. Neuropediatrics 1994;25:172-5.

29 Neil JJ, Shiran SI, McKinstry RC, et al. Normal brain in human newborns: apparent diffusion coefficient and diffusion anisotropy measured by using diffusion tensor MR imaging. Radiology 1998;209:57-66.

\section{ADC web submission and review system}

The Editors of $A D C$ are pleased to inform authors and reviewers of its new online submission and review system. Developed by Highwire Press (CA, USA), Bench > Press is a fully integrated electronic system which uses the internet to allow rapid and efficient submission of manuscripts, and for the peer review process to be conducted entirely online. We are the first journal of the BMJ publishing group to go online in this way; the aim, apart from saving trees, is to speed up the frequently frustrating progress from submission to publication.

Authors can submit their manuscript in any standard word processing software. Standard graphic formats acceptaed include: .jpg, .tiff, .gif, eps, etc. The text and graphic files are automatically converted to PDF for ease of distribution and reviewing purposes. Authors are asked to approve their submission before it formally enters the reviewing process. On approval, the submission is passed to the editor and/or reviewers via the web. All transactions are secure.

To access the system click on "SUBMIT YOUR MANUSCRIPT HERE" on the ADC homepage: http://www.archdischild.com, or you can access the submission site directly at http://submitadc.bmjjournals.com.

We are very excited with this new development and would encourage authors and reviewers to use the system where possible. It is simple to use and should greatly improve on the current peer review process. Full instructions can be found on Bench>Press and ADC online. 